\title{
A critical evaluation of the effectiveness of interventions for improving the well-being of caregivers of children with cerebral palsy: a systematic review protocol
}

Jermaine M. Dambi ${ }^{1,2^{*}}$, Jennifer Jelsma ${ }^{1}$, Tecla Mlambo ${ }^{2}$, Matthew Chiwaridzo ${ }^{1,2}$, Cathrine Tadyanemhandu ${ }^{2,3}$, Mildred T. Chikwanha ${ }^{2,4}$ and Lieselotte Corten ${ }^{1}$

\begin{abstract}
Background: Over the years, family-centered care has evolved as the "gold standard" model for the provision of healthcare services. With the advent of family-centered approach to care comes the inherent need to provide support services to caregivers in addition to meeting the functional needs of children with physical disabilities such as cerebral palsy (CP). Provision of care for a child with CP is invariably associated with poor health outcomes in caregivers. As such, there has been a surge in the development and implementation of interventions for improving the health and well-being of these caregivers. However, there is a paucity of the collective, empirical evidence of the efficacy of these interventions. Therefore, the broad objective of this review is to systematically review the literature on the effectiveness of interventions designed to improve caregivers' well-being.

Methods/design: This is a systematic review for the evaluation of the effectiveness of interventions designed to improve caregivers' well-being. Two independent, blinded, reviewers will search articles on PubMed, Scopus, Web of Science, CINAHL, Psych Info, and Africa-Wide Information using a predefined criterion. Thereafter, three independent reviewers will screen the retrieved articles. The methodological quality of studies meeting the selection criterion will be evaluated using the Briggs Institute checklists. Afterwards, two independent researchers will then apply a preset data-extraction form to collect data. We will perform a narrative data analysis of the final sample of studies included for the review.
\end{abstract}

Discussion: The proposed systematic review will provide the empirical evidence of the efficacy of interventions for improving the well-being of caregivers of children with physical disabilities. This is important given the great need for evidenced-based care and the greater need to improve the health and well-being of caregivers.

Systematic review registration: PROSPERO CRD42016033975

Keywords: Cerebral palsy, Caregiver, Program, Intervention, Burden/strain, Quality of life, Well-being, Evaluation, Systematic review, Protocol

\footnotetext{
* Correspondence: dmbjer001@myuct.ac.za; jermainedambi@gmail.com ${ }^{1}$ Department of Health and Rehabilitation Sciences, Faculty of Health Sciences, University of Cape Town, Anzio Road, Observatory, Cape Town, South Africa

${ }^{2}$ Department of Rehabilitation, College of Health Sciences, University of

Zimbabwe, P.O. Box AV178, Avondale, Harare, Zimbabwe

Full list of author information is available at the end of the article
} 


\section{Introduction \\ Background}

Provision of care to a child with a chronic/long-term health condition has been extensively demonstrated to negatively affect the health and health-related quality of life (HRQoL) of informal caregivers [1-3]. This is exacerbated if the child suffers from a complex neurodevelopmental condition such as cerebral palsy $(\mathrm{CP})[2,3]$. Children with $\mathrm{CP}$ most often present with multiple functional problems and invariably require assistance in dayto-day activities such as feeding, bathing, among others [4]. Furthermore, children with $\mathrm{CP}$ require frequent medical care necessitating the caregivers to visit health institutions thus compounding the magnitude of the perceived burden of care [5]. Consequently, caregiving for a child with $\mathrm{CP}$ is often associated with anxiety [6-8], stress $[9,10]$, depression $[8,11-13]$, low self-efficacy [14], financial burden [15, 16], musculoskeletal pain [13, 17], poor physical health, and lower HRQoL in informal caregivers $[3,18]$. It is also known that the functional limitations of the children become more apparent as the child grows older, increasing the magnitude of caregiver burden with the passage of time $[1,3,5,18]$.

Over the past few decades, there has been a paradigm shift in the provision of rehabilitation services with the family-centered approach evolving as the "gold standard" model of service delivery $[19,20]$. There is now a stronger emphasis to provide support services for caregivers in addition to meeting the functional needs of children with CP $[19,21]$. This is justified because there is evidence that poor caregiver health is associated with poorer functional outcomes in children with CP [3, 22]. For optimal rehabilitation outcomes to be achieved, the caregiver is expected to be compliant with attendance to appointment schedules and with instructions regarding facilitation to improve functioning by expediently implementing the prescribed home exercise program [23]. This is important as the neuroplasticity theory emphasizes the importance of constant practice of functional activities in children with CP (after suffering from brain injury), to improve function [24], hence, the need for continued care at home by the caregivers after the hospital-based therapy sessions for optimal functional outcomes. On the same wavelength, economic evaluations in the USA alone have pegged services of informal caregivers at around $\$ 450$ billion in 2011 [25]. This undoubtedly demonstrates that informal caregivers are a vital human resource in the management of patients with long-term health conditions [21, 26, 27].

To this end, there have been attempts to develop supportive interventions aimed at increasing caregiver wellbeing for moral, ethical, and economic reasons [1, 3, 25]. The most commonly cited interventions include educational strategies, e.g., caregivers' training workshops, and psychosocial strategies such as counselling, support groups, cognitive behavioral techniques, and respite care, among others [28-31]. Felicity et al. [28] performed a randomized controlled trial (RCT) in Australia to determine the impact of a family behavioral interventions such as the acceptance and commitment therapy on the well-being of caregivers of children with traumatic brain injury $(N=59)$. The results indicated that family behavioral interventions may lead to improvements in caregivers' self-efficacy, confidence, family adjustment, and psychosocial well-being. Moreover, support groups have been demonstrated to lead to decreases in parental stress, increased psychosocial well-being in domains such as hope, happiness, and self-esteem in Hong Kong caregivers of children with CP [30].

In another study, 26 Indian caregivers of newly diagnosed children with $\mathrm{CP}$ were exposed to an educational program aimed at increasing parental knowledge of $\mathrm{CP}$ [29]. The results revealed that even a single session is enough to increase caregivers' knowledge. Additionally, the authors postulated that knowledgeable caregivers were most likely to adjust to the demands of caregiving [29]. This is further substantiated by findings from a study on 53 Indian caregivers of children with CP. In the aforementioned study, caregivers' level of knowledge of CP was improved after they were exposed to an educational film [31].

However, there is no collective empirical evidence to determine the efficacy of these interventions in improving caregivers' well-being. Additionally, given the heterogeneity of methodologies applied, it is thus important to systematically evaluate the impact of these interventions on caregivers' well-being. Above all, there is an urgent need for evidence-based practice in implementing supportive interventions for caregivers of children with long-term disabilities.

\section{Objectives}

Therefore, the broad objective of this review is to systematically evaluate the effectiveness of interventions designed to improve caregivers' well-being. The specific objectives are to:

1. Identify interventions targeted at improving caregivers' well-being

2. Describe the identified interventions targeted at improving caregivers' well-being

3. Identify the components of the interventions deemed to be effective in improving caregivers' well-being

\section{Methods}

\section{Study registration}

The protocol was structured according to the Preferred Reporting Items of Systematic Reviews and Meta-Analyses 
Protocol (PRISMA-P) guidelines [32] and has been registered on PROSPERO database (Ref: CRD42016033975).

\section{Eligibility criteria}

In selecting the studies, we will apply the following criteria:

\section{Participants}

A previously described selection criterion will be utilized [33]. Studies will be included if the primary respondents were informal caregivers, aged 18 years and above, providing care for children with chronic/long-term health conditions in the age range $0-12$ years. The dynamics of caregiving are dependent on the developmental stage/ chronological age of a child with a physical disability. For instance, physical burden and the overall burden of caregiving is likely to increase as child gets older and heavier and as they enter the teenage years [22]. Additionally, we will include studies on caregivers of children with physical disabilities such as CP, spina bifida, hydrocephalus, and other long-term health conditions such as perinatal stroke, developmental delay, and traumatic brain injury among others. We envisage that the dynamics of providing care for a child with functional limitations are the same, regardless of the causative agent [33]. There will be no limit as to the severity of disability for the studies to be selected. Additionally, for this review, an informal caregiver denotes someone not formally trained and remunerated for assuming the caregiving role. To minimize the effects of confounding variables, studies with caregivers (i) suffering from chronic conditions and (ii) providing care for other children below the age of five or chronically ill relative/spouse will be excluded.

\section{Study designs}

Due to a dearth of RCTs on interventions of caregivers of children with $\mathrm{CP}$, which was revealed in a pilot/preliminary literature search, all quantitative study designs will be considered in this review. Similarly, the preliminary search revealed a paucity in qualitative studies thus the decision to include quantitative designs only.

\section{Interventions and outcomes}

All studies aimed at either development or implementation of interventions for improving the well-being of caregivers of children with a chronic/long-term health condition as exemplified in Table 1 will be included.

\section{Setting}

All study settings will be considered.

\section{Language}

We will only consider full articles published in English, German, French, and Dutch languages. Due to financial challenges, we do not have resources for paying for the translation of articles published in any other language than these.

\section{Information sources \\ Search strategy}

The following databases will be searched: PubMed, EMBASE, Scopus, MEDLINE, Psych INFO, CINAHL, Cochrane library, PEDro, and OT seeker. As this is a scoping review, we will not impose a time limit as to the data of publication of the articles to gather as much empirical evidence as possible. We will also perform manual searches of references of identified articles to search for additional publications. The following key terms will be utilized in search of the literature: "caregivers" OR "care*" OR "mother*" AND "cerebral palsy" OR "physical disability" AND ("physiotherapy" OR "physical therapy" OR "rehabilitation" OR Occupational therapy) AND "intervention" OR "treat" Table 2 is an example of how we will search for the articles in CINAHL database.

\section{Study records \\ Data management}

Retrieved articles will be imported into RevMan (version 5.3) which is a data management program. The electronic searches will also be saved on users' PubMed, Scopus, and EBSCOhost accounts. The principal researcher will create a shared Dropbox folder to facilitate collaboration among reviewers during the data collection and extraction process. Summaries of all the searches will be printed and are to be used as physical backup for the screened articles.

\section{Selection and data collection process}

The principal author (JD) and a second reviewer (MC) will independently search the databases and extract the titles and abstracts for further investigation using a predefined search strategy. Thereafter, two researchers (MTC and CT) will independently apply the predefined selection criterion and retrieve the full manuscripts of articles deemed relevant. Disagreements during the article screening stage will be settled through discussions, and where appropriate, an independent researcher (JJ) not involved in the searching and screening of the articles will make the final decision. The principal researcher (JD) will manually search the reference lists of identified articles to screen for potential articles for inclusion in the systematic review. Lastly, two independent reviewers (LC and TM) will blindly screen the retrieved articles using a standardized data collection form. The two data collection sheets will be reconciled into one data set through discussions between the principal author (JD) and two reviewers (LC and TM). One independent 
Table 1 PICO table

\begin{tabular}{|c|c|c|c|c|c|}
\hline \multirow[t]{2}{*}{ Population } & \multicolumn{2}{|l|}{ Interventions } & \multirow[t]{2}{*}{ Comparison } & \multicolumn{2}{|l|}{ Outcomes } \\
\hline & $\begin{array}{l}\text { Intervention } \\
\text { category }\end{array}$ & Example(s) & & Example(s) outcome(s) & $\begin{array}{l}\text { Example(s) of outcome } \\
\text { measures }\end{array}$ \\
\hline \multirow{8}{*}{$\begin{array}{l}\text { - Primary caregivers } \\
\text { - Informal/unpaid } \\
\text { caregivers } \\
\text {. } 18 \text { years and above }\end{array}$} & Psychosocial & Counselling & $\begin{array}{l}\text { Non-exposed } \\
\text { controls }\end{array}$ & $\begin{array}{l}\text { Caregiver burden/caregiver } \\
\text { strain }\end{array}$ & $\begin{array}{l}\text { 1. Caregiver strain index } \\
\text { 2. Caregiver burden scale }\end{array}$ \\
\hline & Psychosocial & $\begin{array}{l}\text { Group therapy } \\
\text { sessions }\end{array}$ & $\begin{array}{l}\text { Caregivers of healthy } \\
\text { children }\end{array}$ & HRQoL & $\begin{array}{l}\text { 1. EQ-5D } \\
\text { 2. SF-36 } \\
\text { 3. WHO QOLBREF }\end{array}$ \\
\hline & Psychosocial & $\begin{array}{l}\text { Cognitive behavioral } \\
\text { techniques }\end{array}$ & $\begin{array}{l}\text { Caregivers of children } \\
\text { with minor illness }\end{array}$ & Depression & Becky depression scale \\
\hline & Psychosocial & $\begin{array}{l}\text { Cognitive behavioral } \\
\text { techniques }\end{array}$ & & Anxiety & $\begin{array}{l}\text { Hospital anxiety and depression scale } \\
\text { (HADS) }\end{array}$ \\
\hline & \multirow[t]{2}{*}{ Psychosocial } & \multirow{2}{*}{$\begin{array}{l}\text { Cognitive behavioral } \\
\text { techniques }\end{array}$} & & \multirow[t]{2}{*}{ Self-efficacy } & General self-efficacy scale \\
\hline & & & & & $\begin{array}{l}\text { General perceived } \\
\text { self-efficacy scale }\end{array}$ \\
\hline & Educational & Oral lectures & & $\begin{array}{l}\text { Knowledge/information } \\
\text { on cerebral palsy }\end{array}$ & $\begin{array}{l}\text { Knowledge of cerebral } \\
\text { palsy questionnaire }\end{array}$ \\
\hline & $\begin{array}{l}\text { Physical } \\
\text { activity }\end{array}$ & Exercise classes & & Physical health levels & Borg scale \\
\hline
\end{tabular}

reviewer (JJ) will make the final decision if there be any disagreements. Information to be extracted will include the research setting and design, study sample, demographics of the participants, outcome measures, types of interventions, and results.

\section{Outcomes and prioritization Primary outcomes}

For this review, caregiver burden/strain and HRQoL will be the primary outcome measures.

\section{Secondary outcome}

Caregivers' knowledge of cerebral palsy and psychosocial indices such as depression, anxiety, stress, and selfefficacy will be the secondary outcome measures.

Table 2 Search strategy

\begin{tabular}{|c|c|}
\hline Key word & Alternative words \\
\hline caregiver & carer* OR mother* OR parent* OR legal guardian* \\
\hline children & $\begin{array}{l}\text { child* OR paediatric* OR toddler* OR infant* } \\
\text { OR pediatric* }\end{array}$ \\
\hline cerebral palsy & $\begin{array}{l}\text { CP OR physical disability OR disability* OR } \\
\text { neurodev* disorder*OR traumatic brain injur* }\end{array}$ \\
\hline burden & strain OR stress OR burnout \\
\hline $\begin{array}{l}\text { health related } \\
\text { quality of life }\end{array}$ & $\begin{array}{l}\text { quality of life OR HRQoL OR well-being OR } \\
\text { wellness }\end{array}$ \\
\hline interventions & program* \\
\hline evaluation & determination OR measurement \\
\hline physiotherapy & $\begin{array}{l}\text { physical therapy OR rehabilitation OR occupational } \\
\text { therapy OR physical medicine OR physiatrist }\end{array}$ \\
\hline
\end{tabular}

Risk of bias (or "quality") individual studies

Although random control trials (RCTs) are considered as the gold standard of evidence of efficacy of health care interventions, a preliminary search revealed a dearth of these study designs. We will consequently consider all quantitative designs, i.e., randomized controlled trials, quasi-experimental designs, case series, and comparable cohort/case control studies. To ensure internal and external validity of the selected studies, we will utilize The Briggs Institute checklists (see Additional files 1,2 , and 3 ) to assess the methodological quality of the studies. Two independent reviewers will assess the selected papers (CT and MTC) prior inclusion, and any disagreements will be resolved through discussions with a third independent reviewer (JJ).

\section{Best evidence synthesis}

A preliminary/pilot search revealed a heterogeneity of caregivers' well-being outcome measures. We will therefore perform a narrative/descriptive synthesis of the identified studies, as a meta-analysis would not be feasible. Where there is missing data, we will contact the researchers through email so that studies can be evaluated on the best available evidence.

\section{Discussion}

Given the impact of provision of care for a child with a long-term physical disability/long-term health condition on the caregivers HRQoL, it is important to identify and evaluate the effects of interventions for improving caregivers' well-being. This is essential as there is now a greater call for the improvement of the HRQoL of 
caregivers in addition to improving the HRQoL and functional outcomes in children with disabilities. This review will thus inform health care practitioners and researchers alike of the most practical and feasible methods of improving caregivers' well-being within the confines of available resources. Further, findings can be used to design holistic and multimodal interventions aimed at improving caregivers' well-being.

\section{Additional files}

Additional file 1: JBI critical appraisal checklist for randomised control/ pseudo-randomised trial. (DOC $113 \mathrm{~kb}$ )

Additional file 2: JBI critical appraisal checklist for descriptive/case series. (DOC 107 kb)

Additional file 3: JBI critical appraisal checklist for comparable cohort/case control. (DOC $107 \mathrm{~kb}$ )

\section{Abbreviations}

CINAHL, Cumulative Index of Nursing and Allied Health Literature; CP, cerebral palsy; HRQoL, health-related quality of life; PRISMA-P, Preferred Reporting Items of Systematic Reviews and Meta-Analyses Protocol; RCT, randomized controlled trials; UCT, University of Cape Town

\section{Acknowledgements}

The systematic review is part of the principal investigators' PhD physiotherapy dissertation work. The University of Cape Town (UCT) has provided a scholarship to the principal investigator (JD) to pay for tuition fees through the JW Jagger Centenary Gift School scholarship. There was no external funding for the present protocol; however, the Faculty of Health Sciences Library (UCT) provided technical support. Appreciation also goes to the Professor MM Chidzonga for the unwavering support and to the University of Zimbabwe for partially funding the studies.

\section{Authors' contributions}

JD was primarily responsible for protocol writing. JD, JJ, and TM were involved in the conceptualization of the study. LC, CT, MTC, and MC edited the protocol. JD and $M C$ were responsible for searching the literature and data management. MTC, CT, JJ, TM, and LC were responsible for the article screening, data extraction, and quality assurance. All authors read and approved the final manuscript.

\section{Competing interests}

The authors declare that they have no competing interests.

\section{Author details}

${ }^{1}$ Department of Health and Rehabilitation Sciences, Faculty of Health Sciences, University of Cape Town, Anzio Road, Observatory, Cape Town, South Africa. ${ }^{2}$ Department of Rehabilitation, College of Health Sciences, University of Zimbabwe, P.O. Box AV178, Avondale, Harare, Zimbabwe. ${ }^{3}$ University of Witwatersrand, Johannesburg, South Africa. ${ }^{4}$ Stellenbosch University, Stellenbosch, South Africa.

Received: 3 March 2016 Accepted: 23 June 2016

Published online: 13 July 2016

\section{References}

1. Raina P, Donnell MO, Schwellnus H, Rosenbaum P, King G, Brehaut J, et al. Caregiving process and caregiver burden: conceptual models to guide research and practice. BMC Pediatr. 2004;4:1-13.

2. Raina $P, O^{\prime}$ Donnell M, Rosenbaum P, Brehaut J, Walter SD, Russell D, et al. The health and well-being of caregivers of children with cerebral palsy. Pediatrics [Internet]. 2005 [cited 2011 Jul 11];115:e626-36. Available from: http://www.ncbi.nlm.nih.gov/pubmed/15930188
3. Dambi JM, Jelsma J. The impact of hospital-based and community based models of cerebral palsy rehabilitation: a quasi-experimental study. BMC Pediatr. 2014;14:1-10.

4. Martin B, Murray G, Peter R, Alan L, Nigel P. Proposed definition and classification of cerebral palsy, April 2005.pdf. Dev Med Child Neurol. 2005:47:571-6.

5. Dambi J, Chivambo G, Chiwaridzo M, Matare T. Health-related quality of life of caregivers of children with cerebral palsy and minor health problems in Zimbabwe: a descriptive, comparative cross-sectional study. Int J Sci Res Publ. 2015;5:697-703.

6. Palsili S, Anksiyete A, Üniversitesi H, Fakültesi T, Fiziksel T, Nöroloji P, et al. Anxiety and depression levels in mothers of children with cerebral palsy. Turkish J Phys Med Rehabil. 2006;53:2006-8.

7. Cohen E, Biran G, Aran A, Gross-Tsur V. Locus of control, perceived parenting style, and anxiety in children with cerebral palsy. J. Dev. Phys. Disabil. [Internet]. 2008 [cited 2012 Nov 3];20:415-23. Available from: http:// www.springerlink.com/index/10.1007/s10882-008-9106-8

8. Zanon MA, Batista NA. Quality of life and level of anxiety and depression in caregivers of children with cerebral palsy [Internet]. 2012. p. 392-6. Available from: www.scielo.br/pdf/rpp/v30n3/en_13.pdf

9. Manuel J, Naughton MJ, Balkrishnan R, Smith BP, Koman LA. Stress and adaptation in mothers of children with cerebral palsy. 2001.

10. Skok A, Harvey D, Reddihough D. Perceived stress, perceived social support, and wellbeing among mothers of school-aged children with cerebral palsy. J Interllectual Dev Disabil. 2006;31:53-7.

11. Sajedi F, Alizad V, Malekkhosravi G, Karimlou M, Vameghi R. Depression in mothers of children with cerebral palsy and its relation to severity and type of cerebral palsy. Acta Medica Iranica. 2010;48(4):250-254.

12. Patel V, Abas M, Broadhead J, Todd C, Reeler A. Depression in developing countries: lessons from Zimbabwe. Br Med J. 2001;322:482-4.

13. Kaya K, Unsal-delialioglu S, Ordu-gokkaya NK, Ozisler Z, Ergun N, Ozel S, et al. Musculo-skeletal pain, quality of life and depression in mothers of children with cerebral palsy. Disabil Rehabil. 2010;32:1666-72.

14. Khan F, Pallant J, Brand C. Caregiver strain and factors associated with caregiver self-efficacy and quality of life in a community cohort with multiple sclerosis. Disabil. Rehabil. [Internet]. 2007 [cited 2014 Dec 1];29:1241-50. Available from: http://www.ncbi.nlm.nih.gov/ pubmed/17653999

15. Mbugua MN, Kuria MW, Ndetei DM. The prevalence of depression among family caregivers of children with intellectual disability in a rural setting in Kenya. Int J Family Med. [Internet]. 2011 [cited 2012 Nov 7];534513. Available from: http://www.pubmedcentral.nih.gov/articlerender. fcgi?artid=3263839\&tool=pmcentrez\&rendertype=abstract

16. Wijesinghe CJ, Fonseka P, Hewage CG. The development and validation of an instrument to assess caregiver burden in cerebral palsy: caregiver difficulties scale. Ceylon Med J. 2013;58:162-7.

17. Tong HC, Haig AJ, Nelson VS, Kandala G, Shin KY. Low back pain in adult female caregivers of children with physical disabilities. Archives of Pediatric and Adolescence Medicine. 2013:157:1128-33

18. Pousada M, Guillamón N, Hernández-Encuentra E, Muñoz E, Redolar D, Boixadós $\mathrm{M}$, et al. Impact of caring for a child with cerebral palsy on the quality of life of parents: a systematic review of the literature. J. Dev. Phys. Disabil. [Internet]. 2013 [cited 2014 Jul 12];25:545-77. Available from: http:// link.springer.com/10.1007/s10882-013-9332-6

19. Kuo DZ, Houtrow AJ, Arango P, Kuhlthau K a, Simmons JM, Neff JM. Familycentered care: current applications and future directions in pediatric health care. Matern. Child Health J. [Internet]. 2012 [cited 2014 Sep 8];16:297-305. Available from: http://www.pubmedcentral.nih.gov/articlerender. fcgi?artid=3262132\&tool=pmcentrez\&rendertype=abstract

20. Kuhlthau K a, Bloom S, Van Cleave J, Knapp A a, Romm D, Klatka K, et al. Evidence for family-centered care for children with special health care needs: a systematic review. Acad. Pediatr. [Internet]. Elsevier Ltd; 2011 [cited 2014 Sep 5];11:136-43. Available from: http://www.ncbi.nlm.nih.gov/ pubmed/21396616

21. Byrne MB, Hurley DA, Daly L, Cunninghamt CG. Health status of caregivers of children with cerebral palsy. Child Care Health Dev. 2010;36:696-703.

22. Dambi JM, Jelsma J, Mlambo T. Caring for a child with cerebral palsy: the experience of Zimbabwean mothers. African J Disabil. 2015;4:1-10. Available from: http://www.ajod.org/index.php/ajod/article/view/168.

23. Jack K, McLean SM, Moffett JK, Gardiner E. Barriers to treatment adherence in physiotherapy outpatient clinics: a systematic review. Man. Ther. 
[Internet]. Elsevier Ltd; 2010 [cited 2013 Mar 8];15:220-8. Available from: http://www.pubmedcentral.nih.gov/articlerender.fcgi?artid=2923776\&tool= pmcentrez\&rendertype $=$ abstract

24. Aisen ML, Kerkovich D, Mast J, Mulroy S, Wren T Al, Kay RM, et al. Cerebral palsy: clinical care and neurological rehabilitation. Lancet Neurol. [Internet]. Elsevier Ltd; 2011 [cited 2011 Aug 19];10:844-52. Available from: http:// www.ncbinlm.nih.gov/pubmed/21849165

25. Gibson MJ, Houser A.Valuing the invaluable: a new look at the economic value of family caregiving [Internet]. Public Policy Inst. 2007 [cited $2015 \mathrm{Ju}$ 7]. p. 1-12. Available from: http://www.aarp.org/relationships/caregiving/ info-2007/ib82_caregiving.html

26. Bugge C, Alexander H, Hagen S, Factors S, Affect T, Strain C. Stroke patients' informal caregivers. Stroke. 1999;1517-23. Available from: http://stroke. ahajournals.org/content/30/8/1517.full.pdf+html

27. Brouwer WBF, van Exel NJ a, van den Berg B, van den Bos $G$ a M, Koopmanschap $\mathrm{M}$ a. Process utility from providing informal care: the benefit of caring. Health Policy [Internet]. 2005 [cited 2011 Nov 21];74:85-99. Available from: http://www.ncbi.nlm.nih.gov/pubmed/16098415

28. Brown FL, Whittingham K, Boyd RN, McKinlay L, Sofronoff K. Does Stepping Stones Triple P plus Acceptance and Commitment Therapy improve parent, couple, and family adjustment following paediatric acquired brain injury? A randomised controlled trial. Behav Res Ther. [Internet]. 2015;73:58-66. Available from: http://10.1016/j.brat.2015.07.001

29. Karande S, Patil S, Kulkarni M. Impact of an educational program on parental knowledge of cerebral palsy. Indian J. Pediatr. [Internet]. 2008;75: 901-6. Available from: http://www.ncbi.nlm.nih.gov/pubmed/18810366

30. Fung BKK, Ho SMY, Fung ASM, Leung EYP, Chow SP, Ip WY. The development of a strength-focused mutual support group for caretakers of children with cerebral palsy. East Asian Arch. Psychiatry. 2011;21:64-72.

31. Arora SK, Aggarwal A, Mittal H. Impact of an educational film on parental knowledge of children with cerebral palsy. Int. J. Pediatr. [Internet]. Hindawi Publishing Corporation; 2014 [cited 2014 Jun 3];2014:573698. Available from: http://www.pubmedcentral.nih.gov/articlerender. fcgi?artid=3963117\&tool=pmcentrez\&rendertype $=$ abstract

32. Moher D, Shamseer L, Clarke M, Ghersi D, Liberati A, Petticrew M, et al. Preferred reporting items for systematic review and meta-analysis protocols (PRISMA-P) 2015 statement. Syst Rev. [Internet]. 2015;4:1. Available from: http://www.systematicreviewsjournal.com/content/4/1/1

33. Dambi JM, Jelsma J, Mlambo T, Chiwaridzo M, Dangarembizi-Munambah N, Corten L. An evaluation of psychometric properties of caregiver burden outcome measures used in caregivers of children with cerebral palsy: a systematic review protocol. Syst. Rev. [Internet]. Systematic Reviews; 2016;5:42. Available from: http://www.systematicreviewsjournal.com/content/5/1/42

\section{Submit your next manuscript to BioMed Central and we will help you at every step:}

- We accept pre-submission inquiries

- Our selector tool helps you to find the most relevant journal

- We provide round the clock customer support

- Convenient online submission

- Thorough peer review

- Inclusion in PubMed and all major indexing services

- Maximum visibility for your research

Submit your manuscript at www.biomedcentral.com/submit

) Biomed Central 